\title{
Cysteine as an Eco-Friendly Corrosion Inhibitor
}

\author{
Perihan Hussein El-Shafei, Mohamed S. El-Deab, M. A. Sadek and Hany A. Elazab
}

\begin{abstract}
In this paper, the aim was finding the most efficient corrosion inhibitor for mild steel placed in a $0.5 \mathrm{M}$ Sulfuric acid. The comparison was implemented between Cysteine (an eco-friendly corrosion inhibitor) and 4 different Ions-Cysteine Inhibitors (CopperCysteine, Nickel-Cysteine, Iron-Cysteine, and Cobalt-Cysteine). The solutions were prepared and evaluated while placed with a working electrode of mild steel with a copper rod attached to its end. To determine the best eco-friendly corrosion inhibitors two experiments were implemented: Electrochemical Impedance Spectra, and Linear Polarization. By the end of the experiment it was found that CopperCysteine was the most efficient eco-friendly corrosion inhibitor for mild steel with maximum inhibition efficiency of $91 \%$, followed by Nickel-Cysteine with maximum inhibition efficiency of $90.9 \%$. IronCysteine had a maximum inhibition efficiency of $86.04 \%$ followed by Cobalt-Cysteine with a maximum inhibition efficiency of $84.3 \%$. These percentages are at highest concentration of the ion, however in this submitted paper the mentioned comparisons will be at moderate concentrations of 25 micro-M ions rather than the 50 micro-M concentration.
\end{abstract}

Keywords - Cysteine, corrosion, inhibitors.

\section{INTRODUCTION}

Corrosion is a major issue worldwide, whether in a production process, in building fields, or even in house wear. Over the years the problem was introduced as a field of science - Corrosion Science- and the constant search for solutions has grown with respect to time. At the beginning the ultimate aim was to find solution for corrosion to prevent it, or slow its rate, neglecting any other factors that might outcome from the approached corrosion retardant such as BTA. Yet again, as time passed these factors were found to be severe, whether it harms the environment, or harm the people themselves. Hence, the beginning of the eco-friendly corrosion retardants search began. After the declaration of BTA as a toxic inhibitor; as it was very popular since the 1960s, the search for ecofriendly inhibitors has been very foundant. Around the beginning of the 2000s cysteine has been tested as an ecofriendly corrosion inhibitor. Then over time cysteine complexes were invistigated as well, for example Cupper(11)Cysteine [1-3]. Hence, Cysteine was tested in this experiment

Perihan Hussein El-Shafei, Faculty of Engineering, Chemical Engineering Department, The British University in Egypt (BUE), El Sherouk City, Cairo, Egypt.

Mohamed S. El-Deab, Faculty of Science, Chemistry Department, Cairo University, Cairo, Egypt.

M. A. Sadek, Faculty of Engineering, Chemical Engineering Department, The British University in Egypt (BUE), El Sherouk City, Cairo, Egypt.

Hany A. Elazab, Faculty of Engineering, Chemical Engineering Department, The British University in Egypt (BUE), El Sherouk City, Cairo, Egypt. as an eco-friendly corrosion inhibitor for mild steel, and four of its complexes, with Iron, Copper, Cobalt, or nickel ions. Corrosion usually occurs due to loss in Gibbs energy. Metals struggle to stay in their manufacture form; accordingly, they tend to undergo an oxidation-reduction reaction to go back to their normal oxidation form. This occurs when the environment in which they exist enhances such reaction. The presence of Moisture or oxygen, and interface promotes the driving force of metals to corrode. In addition to that, when the environment in which the metal is placed is aggressive it will increase the rate of corrosion. Since this paper is dedicated to study corrosion inhibitors effect on mild steel, then steel is picked to explain corrosion as shown below. Usually steel's corrosion product is what we call as rust, which forms on the surface of the steel. This may be explained in two equations as Bill and Gareth explained in their paper [4].

$$
F e \rightarrow F e^{n+}+n \text { (electrons) }
$$

Yet, this is only considered half of the process in which we didn't consider the environment that encourages the rusting. In the presence of water or oxygen or both, Steel corrodes forming a rust of iron hydroxide. This product as any other corrosion product is unlikely to be wanted. This process is shown in the below equation:

$$
\mathrm{O}_{2}+2 \mathrm{H}_{2} \mathrm{O}+4 e^{-} \rightarrow 4 \mathrm{OH}^{-}
$$

Upon, adding both equations together, and putting aside the electrons for simplicity, the following equation may be deduced:

$$
\begin{aligned}
2 \mathrm{Fe}+\mathrm{O}_{2}+2 \mathrm{H}_{2} \mathrm{O} & \rightarrow 2 \mathrm{Fe}(\mathrm{OH})_{2} \\
\text { Iron }+ \text { Oxygen }+ \text { Water } & \rightarrow \text { Iron Hydroxide }
\end{aligned}
$$

Finally, since oxygen does dissolve in water easily - with excess oxygen - its rapidly reacts with the formed iron hydroxide to produce brown rust or as it is scientifically called hydrated iron oxide, as shown below:

$$
4 \mathrm{Fe}(\mathrm{OH})_{2}+\mathrm{O}_{2} \rightarrow 2 \mathrm{H}_{2} \mathrm{O}+2 \mathrm{Fe}_{2} \mathrm{O}_{2} \cdot \mathrm{H}_{2} \mathrm{O}
$$

Usually, for steel corrosion to take place three main components have to exist [5]. A cell incorporating a cathode and an anode. So, that $\mathrm{e}^{-}$would travel from the anode to the cathode. Moisture/water that acts as the medium where electrons travel through. Oxygen, which reacts with the iron to form ferric oxide/red rust or ferrous oxide/black stain.

There are several methods to prevent from corrosion including coating, sacrificial anode, and inhibitors. Corrosion inhibitors are used since the 19th century to protect metals in many processes. These processes include oil wells with high acidity content, cooling systems and aggressive water, and acid picking. Approaching the 1960's electrochemistry started to be the main evaluator of corrosion inhibitors, hence developing the inhibitors technology [6-8]. Corrosion 
inhibitors can be synthesized or existing in nature. They can be classified into two main groups: organic, and non-organic [6-8]. The used Inhibitor in this experiment is Cysteine which is an organic inhibitor that implements both a Cathodic and an anodic change, while adsorbs on the surface of the metal to protect it. Cysteine contains a three hetero atoms $\mathrm{S}, \mathrm{N}$, and $\mathrm{O}$ [1-2,6-8].

\section{METHODOLOGY}

Cysteine is prepared in five different concentrations 1, 2, 3, 4 , and $\mathrm{mM}$. While the ions are prepared in three different concentrations each $15,25,50$ micro-M. The ions concentrations are placed in $2 \mathrm{mM}$ Cysteine to find their effect on moderate Cysteine concentration. In this paper the moderate concentrations of ions are only considered, thus the 25 micro-M. The other concentrations almost obey the same trend of results. The mild steel cylindrical sample of diameter $8 \mathrm{~mm}$ and $5 \mathrm{~cm}$ length is connected with a copper rod to act as a working electrode in the three electrode system that will be used for both potentio-stat tests as shown in the Fig. 1 and Fig. 2.

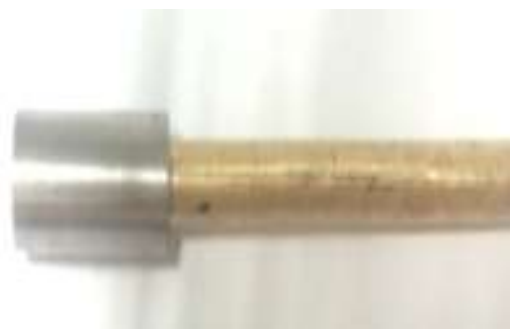

Fig. 1. Working Electrode.

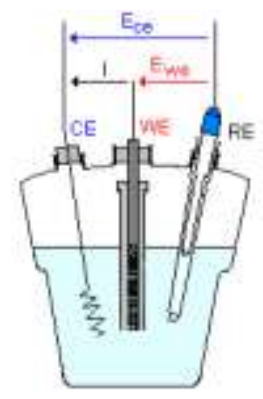

Fig. 2. Three Electrode System.

\section{RESULTS AND DISCUSSION}

\section{A. Impedance}

Impedance measures the resistance to current flow within the electrochemical cell (three electrode system) as the diameter of the half circle increase, this means that the resistance to current flowing increase, in other words the retarding to electrons flowing increases which means the inhibition efficiency of the inhibitor increases and corrosion rate decreases.

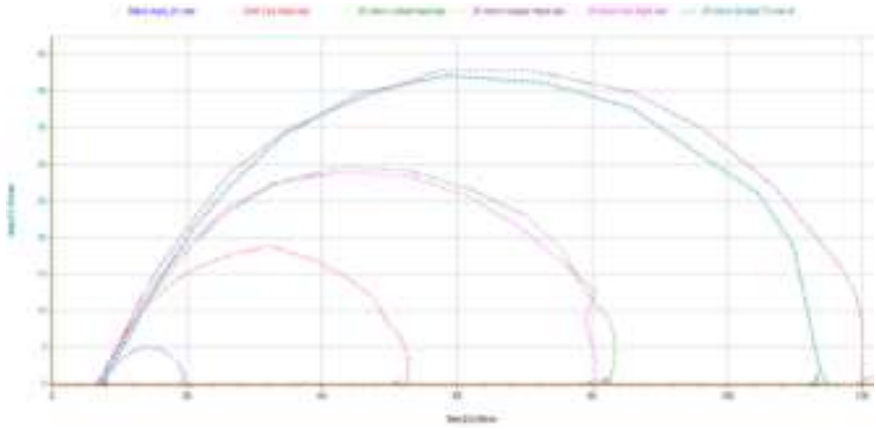

Fig. 3. Nyquist plots of mild steel in $0.5 \mathrm{M} \mathrm{H} 2 \mathrm{SO} 4$ containing (A) 0 , (B) $2 \mathrm{~m}-\mathrm{M}$ Cysteine, (C) 25 micro-M Iron ions + 2m-M Cysteine, (D) 25micro-M Cobalt ions $+2 \mathrm{~m}-\mathrm{M}$ Cysteine, (E) 25micro-M Nickel ions + 2m-M Cysteine, (F) 25 micro-M Copper ions + 2m-M

Cysteine.

The above curve shows the impedance curves of the blank, 2Mm Cysteine, and Cysteine- ions Inhibitors at 25 micro-M Ions concentrations. As it can be seen in the curve at 25 micro$M$ ion concentration all the ions induced higher resistance than Cysteine on its own. However, at this concentration of ions, the Iron- Cysteine fell back to the least favorable Cysteine-Ion inhibitor switching places with Copper-Cysteine inhibitor that accomplished the highest retarding ability within all 25 micro$\mathrm{M}$ ion concentrations. With this said, Copper is the most favorable ion as the ion concentration tend to be moderate (25 micro-M), followed by Nickel, then Cobalt, then Iron.

To calculate the efficiency of the inhibitor with respect to the impedance experiment the following equation is used:

$$
I E \%=\left(1-\frac{R_{P_{\text {Blmnk }}}}{R_{P_{\text {hhihived }}}}\right) \times 100
$$

Where;

IE\% is the inhibitor efficiency

$R_{P_{\text {Blank }}}$ is the polarization resistance of the blank sample equal to the Diameter of the half circle.

$R_{P_{\text {Yhlibirem }}}$ is the polarization resistance of inhibited sample equal to the Diameter of the half circle.

TABLE I

INHIBITION EFFICIENCY OF THE SET WITH RESPECT TO IMPEDANCE EXPERIMENT.

\begin{tabular}{lcc}
\hline IV. BLEND & $\begin{array}{c}\text { Diameter } \\
(\text { ohm })\end{array}$ & IE\% \\
\hline 2 m-M Cysteine & 45.4 & 74.6 \\
25 micro-M Iron & 73.46 & 84.3 \\
25 micro-M Cobalt & 73.46 & 84.3 \\
25 micro-M Nickel & 107.2 & 89.2 \\
25 micro-M Copper & 113.2 & 89.8 \\
\hline
\end{tabular}

As mentioned before Copper showed the highest resistance at 25 micro-M, with an inhibition efficiency $89.8 \%$. Which is higher than that of Iron 15 micro-M that was 86.04. Nickel 
also conducted higher resistance than that of Iron 15 micro-M,

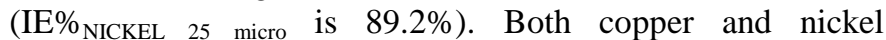
implemented almost the same inhibition efficiency, but copper implemented a slightly higher efficiency. Cobalt and Iron implemented an almost equal efficiency, however if we compare these results to the Iron 15 micro-M we will deduce that 25 micro-M Copper is the best option, followed by the 25 micro-M Nickel, then the 15 micro-M Iron, then the 15 microM Nickel, and finally the 25 micro-M Cobalt.

\section{B. Polarization}

Polarization measures Current Vs. Voltage. Upon taking a certain constant voltage on the $\mathrm{Y}$-axis and moving along that line each curve will show a different current value on the $\mathrm{X}$ axis. The inhibitor with the lowest current at the same voltage is the inhibitor with the highest inhibition efficiency and allowing the minimum corrosion rate. The Constant Cathodic Voltage is taken as $-0.6 \mathrm{~V}$, and the constant Anodic Voltage is $-0.4 \mathrm{~V}$.

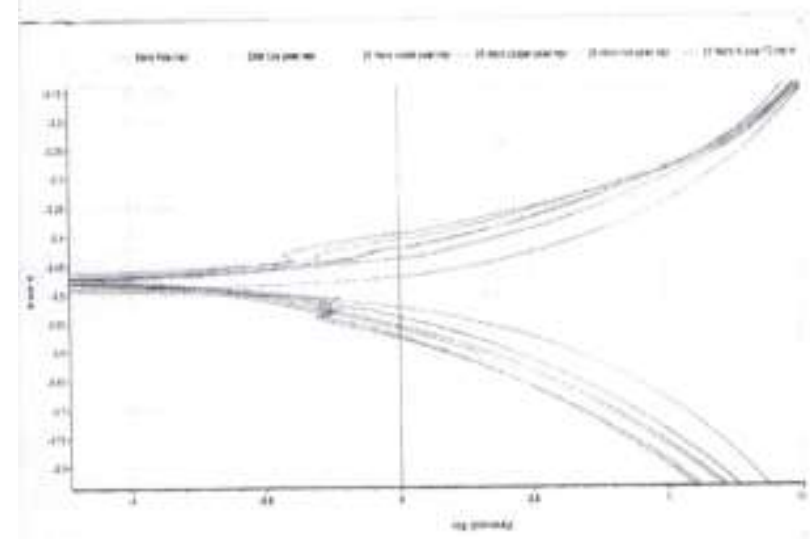

Fig. 4. Polarization Curve of mild steel in $\mathrm{H} 2 \mathrm{SO} 4$ containing (a) 0 , (b) $2 \mathrm{~m}-\mathrm{M}$ Cysteine, (c) 25 micro-M Iron ions + 2m-M Cysteine, (d) 25micro-M Cobalt ions $+2 \mathrm{~m}-\mathrm{M}$ Cysteine, (e) 25micro-M Nickel ions +2m-M Cysteine, (f) 25 micro-M Copper ions + 2m-M Cysteine.

The above figure shows the change in current in blank solution, 2Mm Cysteine, and Ion-Cysteine at 25 micro-M ion concentration. The anodic and cathodic reactions tend to have similar behavior with respect to ions conducting current. This can be easily deduced from the curve where copper conducts the least current, followed by Nickle, then Iron and Cobalt. This behavior is the exact behavior observed in the impedance result. To calculate the efficiency the following equation is used:

$$
\mathrm{IE} \%=\left(1-\frac{I_{\text {Ghhibinga }}}{I_{\text {Blank }}}\right) \times 100
$$

Where;

$\mathrm{I}_{\text {Inhibited }}$ is the current induced when the inhibitor is added.

$\mathrm{I}_{\mathrm{Blank}}$ is the induced current when no inhibitor is added.
TABLE II

INHIBITION EFFICIENCY OF THE SET WITH RESPECT TO POLARIZATION EXPERIMENT.

\begin{tabular}{|c|c|c|c|c|}
\hline I. BLEND & $\underline{\mathbf{I}}_{\text {Cathodic }}$ & $\underline{\mathrm{IE} \%}$ & $\underline{\mathbf{A}}_{\text {Anodic }}$ & $\underline{\mathrm{IE} \%}$ \\
\hline Blank & 4.51 & - & 5.14 & - \\
\hline 2 m-M Cysteine & 2.6 & 47.7 & 2.59 & 51.8 \\
\hline 25 micro-M Iron & 1.40 & 69 & 0.86 & 83.3 \\
\hline 25 micro-M Cobalt & 1.49 & 67 & 1.26 & 75.5 \\
\hline 25 micro-M Nickel & 2.06 & 54.3 & 1.75 & 66 \\
\hline 25 micro-M Copper & 0.245 & 61 & 1.87 & 63.6 \\
\hline
\end{tabular}

With respect to the cathodic reaction the highest efficiency is accomplished by copper with $69 \%$, followed by Nickel with $67 \%$, then Iron with $61 \%$, then Cobalt with $54.3 \%$. Thus, this is a similar behavior to that shown in the impedance result. However, with respect to the anodic reaction the order seems the same except that iron tends to conduct more current than Cobalt. In the impedance it was stated that the difference between both ions' efficiency is $0.3 \%$ which is very low, but after re-studying the polarization technique it can be deduced that Iron at 25 micro-M is a better inhibitor than Cobalt. This can be justified later on in the corrosion rate calculations. According to the efficiencies so far copper 25 micro-M tends to be the most favorable, after that Nickle 25 micro-M, then nickel 15 micro-M, and then Iron 15 micro-M.

\section{A. Corrosion Rate}

The below table contains the corrosion rate in mpy (miles per year), Corrosion Voltage, Corrosion Current, and $\beta_{c}$ and $\beta_{\mathrm{a}}$.

TABLE III

CORROSION VALUES OF THE SET ACCORDING TO POLARIZATION RESULTS

\begin{tabular}{cccccc}
\hline Blend & $\mathrm{E}_{\text {Corr }} / \mathrm{mV}$ & $\mathrm{I}_{\text {Corr }} / \mu \mathrm{A}$ & $\beta_{\mathrm{c}} / \mathrm{mV}$ & $\beta_{\mathrm{a}} / \mathrm{mV}$ & $\begin{array}{c}\text { Corr. } \\
\text { Rate/mpy }\end{array}$ \\
\hline Blank & -509.531 & 1687.498 & 220.6 & 220.1 & 142.351 \\
2m-M Cysteine & -503.871 & 775.559 & 188 & 181.4 & 65.423 \\
& & & & & \\
25micro-M Copper & -476.235 & 234.099 & 162.4 & 112.3 & 19.748 \\
& & & & & \\
25micro-M Nickel & -494.161 & 335.138 & 168.7 & 141.8 & 28.271 \\
& & & & & \\
25micro-M Cobalt & -495.518 & 502.082 & 175.3 & 158.4 & 42.353 \\
& & & & & \\
25micro-M Iron & -501.114 & 461.082 & 167.6 & 156.7 & 38.895
\end{tabular}


The above Table shows that Copper causes the least corrosion rate with value 19.75 mpy, followed by Nickel with value 28.27 mpy, combining the 15 micro-M concentrations, third place would go to Nickel at 15 micro-M with value $34.8 \mathrm{mpy}$, and then Iron would be fourth preferable at concentration 15 micro-M with corrosion rate value 36.4. This priority order justifies the priority order previously discussed within the polarization curves and the impedance results.

\section{CONCLUSION}

The aim of this paper was to test different eco-friendly corrosion inhibitors to protect mild steel in an acidic medium of $0.5 \mathrm{M} \mathrm{H}_{2} \mathrm{SO}_{4}$. The impedance experiment was implemented on a cylindrical mild steel sample with a copper rod as a working electrode, a spiral platinum as a counter electrode, and silver/silver chloride as a reference electrode. The Cysteine's highest efficiency was around $85 \%$, and the $2 \mathrm{mM}$ Cysteine was around $75 \%$. The different ions were added to the $2 \mathrm{mM}$ Cysteine. The Copper-Cysteine proved that it was the best inhibitor within moderate ( 25 micro-molar). Nickel was quite the good inhibitor as well, it was the second best option at moderate concentrations. Iron-Cysteine was weaker than Nickel-Cysteine and Copper-Cysteine yet it was still better than the Cobalt-Cysteine which was proven to be the weakest among the four Ions-Cysteine inhibitors. However, they all exhibited better inhibition efficiency higher than Cysteine on its own. The Polarization experiment was implemented on the same impedance sample and the same three electrode system. The results of the polarization experiment where of a same trend as that of impedance, the only difference that it clarified which inhibitor was better at concentrations where two inhibitors showed almost the same resistance in the impedance test. For instance, it clarified that Cobalt-Cysteine was the weakest inhibitor among the four Ion-Cysteine inhibitors especially at moderate concentration when impedance showed cobalt and iron almost the same. In addition to that it clearly showed Copper-Cysteine stronger than Nickel-Cysteine at times when it showed on the impedance experiment that they were of almost equal efficiencies. In conclusion, Copper-Cysteine is a highly stable corrosion inhibitor at moderate and high concentration of ions, and Nickel-Cysteine is highly stable as well, and a perfect second option after Copper-Cysteine.

\section{ACKNOWLEDGMENT}

The authors thank the British University in Egypt (BUE) for supporting this research.

\section{REFERENCES}

[1] El-Deab, M. S. (2011). Interaction of cysteine and copper ions on the surface of iron: EIS, polarization and XPS study. Materials Chemistry and Physics 129, 223.

https://doi.org/10.1016/j.matchemphys.2011.03.083

[2] Sonisheeba, R., Angel, P., Sathiyabama, J., Sivakumar, S., raj, J. T., Venkatesan, R., \& Raja, A. S. (2014). Corrosion Inhibition by Cysteine An Over View. International Journal of Advanced research in Chemical Science 1,101.

[3] Cang, H., Fei, Z., Shi, W., \& Xu, Q. (2012). Experimental and Theoretical Study for Corrosion Inhibition of Mild Steel by L-Cysteine. International Journal of Electrochemical Science 7,10121.
[4] Popoola, L. T., Grema, A. S., Latinwo, G. K., Gutti, B., \& Balogun, A. S. (2013). Corrosion problems during oil and gas production and its mitigation. International Journal of Industrial Chemistry 4,1.

https://doi.org/10.1186/2228-5547-4-35

[5] Conley, S. (2013, November). CORROSION MECHANISMS, PROCESSES. Tube \& Pipe Journal.

[6] Shaw, B. A., \& Kelly, R. G. (2006). What is Corrosion? Retrieved from electrochem.

https://www.electrochem.org/dl/interface/spr/spr06/spr06_p24-26.pdf.

[7] Ju, H., Kai, Z.-P., \& Li, Y. (2007). Aminic nitrogen-bearing polydentate Schiff base compounds as corrosion inhibitors for iron in acidic media: A quantum chemical calculation. Corrosion Science 50, 865. https://doi.org/10.1016/j.corsci.2007.10.009

[8] Dariva , C. G., \& Galio , A. F. (2014). Corrosion Inhibitors - Principles, Mechanisms and Applications. Chapter 16, INTECH.

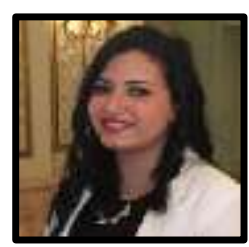

About Author (s):

Eng. Perihan Hussein El-Shafei was graduated from BUE at 2016.

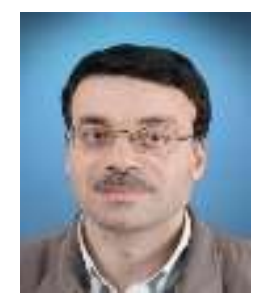

Prof. Mohamed S. El-Deab received his PhD from Cairo University (1999) and was promoted as full Professor of Physical Chemistry- Cairo University on 2010. He received the JSPS post doc fellowship for two years (2001-2003), NEDO research Associate and JSPS long-term invitation fellowship (2004-2007) in the Department of Electronic Chemistry - Tokyo Institute of Technology, Japan. In 2008, he got the prestigious Alexander von Humboldt fellowship to Ulm University-Germany for 21 months. He is the author of 82 international publications which receives more than 2200 citations and h-index of 25 . The major research topics include: Electrocatalysis by nanoparticles, energy conversion systems (FCs), waste water treatment, Biodiesel production.

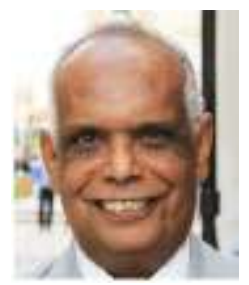

Prof. Shahir Sadek earned his B.Sc. in Chemical Engineering in 1971 from Military Technical College (MTC), followed by minimum CSc. in 1977 from Brno Academy (VAAZ) , CSSR.

Prof. Shahir earned his Ph.D. in June 1981 from the University of Orsay, Paris, France, in Organic chemistry. He worked as lecturer, associate professor and professor in the Chemical Engineering Branch at the Military Technical College in Egypt from 1981 to 1996. Prof. Shahir led the chemical Engineering Department in Higher Technological Institute, $10^{\text {th }}$ of Ramadan City (HTI) from 1996 to 2004. In September 2004, He worked as Associate Dean for October branch of HTI., Associate Dean for Education \& student affairs in HTI, and as Dean of HTI till October 2012. In September 2013 Prof. Shahir joined the British University in Egypt as Head of Chemical Engineering and Vice Dean for research, postgraduate studies and Community Services till now.

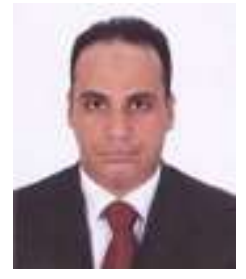

Dr. Hany A. Elazab is a lecturer and program director at the Department of Chemical Engineering, British University in Egypt (BUE), Cairo, Egypt. He earned his $\mathrm{PhD}$ in chemical engineering from Virginia Commonwealth University (VCU) in Richmond, VA, USA. He is currently teaching courses in catalysis, thermodynamics, mass and energy balance. He was awarded the Young Investigator Research Award (YIRG) and High Impact Research Award from the BUE. His research interests include synthesis of nanomaterials, nanoalloys, nanoparticle catalysts, graphene, and graphene-supported catalysts. 